\title{
Grupo de gestantes: uma estratégia de intervenção do PET-Saúde da Família
}

Heloyse Hott Paulino*, Patrícia Souza*, Lucimar Aparecida Britto Codato**, Evelin Massae Ogatta Muraguchi $^{* * *}$, Maura Sassahara Higasi ${ }^{* * *}$ Priscila Casaroto ${ }^{* * * *}$, Margarete Raminelli $* * * * *$

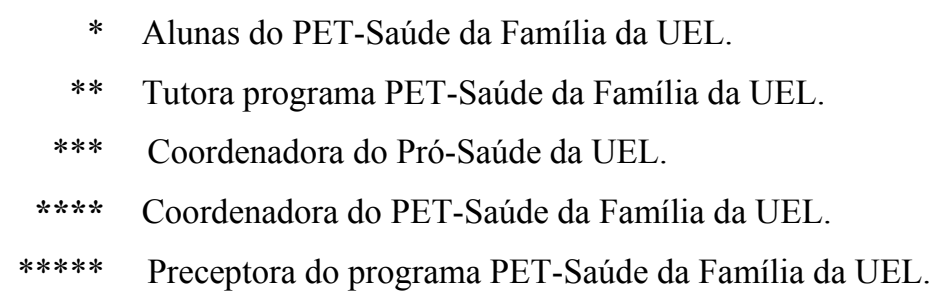

\section{RESUMO}

No ano de 2013, o grupo PET-Saúde da Família Universidade Estadual de Londrina atuou em conjunto com o Programa Rede Mãe Paranaense. Uma das atividades realizadas foi a identificação de fragilidades existentes nas Unidades Básicas de Saúde (UBS) vinculadas ao projeto, obtidas por meio de interações com as equipes multiprofissionais de cada local. A partir desse diagnóstico, o grupo PET, com participação de estudantes de odontologia e enfermagem, juntamente com a equipe de saúde, estabeleceu estratégia de intervenção que pudesse dar respostas positivas para as demandas da UBS. Assim, o grupo trabalhou para a reimplantação do Grupo de Gestantes, com o propósito de contribuir com um melhor acolhimento, integralidade da atenção e interação com as futuras mães, acreditando que essa ação também poderia contribuir com a diminuição de demandas curativas para essa parcela da população e para os seu bebê.

Descritores: Educação em Saúde; Formação de Recursos Humanos; Programa Saúde da Família.

\section{INTRODUÇÃO}

O Projeto PET Saúde da Família da Universidade Estadual de Londrina (UEL) PR tem desenvolvido suas atividades com o propósito fim de contribuir para a implementação da Rede Cegonha/Mãe Paranaense, visando à diminuição da mortalidade materna e infantil no Paraná. O projeto atua em Unidades Básicas de Saúde (UBS) do município de Londrina e também nas cidades de Cambé e Ibiporã.

Uma das atividades realizadas foi a identificação de fragilidades existentes nas UBS vinculadas ao projeto, obtidas por meio de interações com as equipes multiprofissionais de cada local. A partir desse diagnóstico, cada grupo PET, juntamente com as equipes de saúde de cada UBS, estabeleceu estratégias de intervenção que pudessem dar respostas positivas para as demandas particularizadas de cada uma das UBS que recebem alunos do PET-Saúde.

Nesse contexto, o grupo PET-Saúde, composto por estudantes de odontologia e de enfermagem que atua na UBS Maria Anideje, situada em Cambé, PR trabalhou na reimplantação do Grupo de Gestantes, com o propósito de contribuir com um me- 
lhor acolhimento, integralidade da atenção e interação com as futuras mães, acreditando que essa ação também poderia contribuir com a diminuição de demandas curativas para essa parcela da população e para os seu bebê.

Historicamente, sabe-se que na década de 1990, teve início a implementação do Programa Saúde da Família (PSF), com o intuito de contribuir para a construção e a consolidação do Sistema Único de Saúde (SUS), propondo a reorientação do modelo assistencial a partir da atenção básica. ${ }^{1} \mathrm{~A}$ educação em saúde é um instrumento que engaja o profissional com a comunidade, que busca desenvolver nas pessoas o senso de responsabilidade pela saúde. Dessa forma, o PSF prevê o desenvolvimento de práticas de educação em saúde voltadas para a melhoria do autocuidado dos indivíduos. ${ }^{3}$

Dentre as inúmeras ferramentas utilizadas pelos profissionais da atenção básica para promover a saúde das pessoas, a estratégia grupo tem sido bastante incentivada. $^{5} \mathrm{O}$ trabalho grupal pode ser utilizado como estratégia do processo educativo, pois a construção deste acontece a partir das interações entre seres humanos de forma dinâmica e reflexiva. A técnica de trabalho com grupos promove o fortalecimento das potencialidades individuais e grupais, a valorização da saúde, a utilização dos recursos disponíveis e o exercício da cidadania. $^{7}$

A gravidez é um período que provoca várias mudanças físicas, emocionais e sociais. Essas alterações geram sentimentos, como ansiedade, medo, angústia, dúvida, fantasia, entre outros, o que exige uma série de adaptações tanto da mulher como de seu parceiro. ${ }^{6}$ Nesse período de mudanças, o casal necessita obter informações e orientações que auxiliem no desenvolvimento da gestação e no puerpério, sendo portando um período impar para a realização de ações educativas.

O grupo de orientação às gestantes caracteriza-se por uma ação educativa com o objetivo de facilitar a disseminação da informação e apropriação do conhecimento e favorecer a troca de experiências e é de grande importância para as futuras mães conhecerem todo o processo que envolve o ciclo gravídico-puerperal. ${ }^{8}$

O papel do profissional de saúde passa a ser sempre o de capacitar o indivíduo de desenvolver uma determinação da função e não apenas o de prescrever técnicas e ditar normas comportamentais. É imprescindível que se abandone a postura autoritária de educação para a saúde, em detrimento a uma postura de incentivo e motivação, fazendo com que a promoção de saúde deixe de ser uma idéia e passe a ser uma prática rotineira.

\section{METODOLOGIA: DESCRIÇÃO DA ATIVIDADE DESENVOLVIDA PE- LO GRUPO PET-SAÚDE DA FAMÍ- LIA}

\subsection{Identificação da fragilidade}

O grupo PET-Saúde reuniu-se com a equipe multiprofissional da UBS para identificar fragilidades locais, relacionadas ao cuidado da gestante. Foi relatado que o PSF tem encontrado dificuldades em relação à adesão das gestantes nos grupos de orientação, o que resultou na paralisação dessa ação educativa na UBS. Assim, o grupo PET propôs atuar na reimplementação dos grupo de gestantes.

\subsection{Abordagem da gestante}

O Grupo de Orientação à Gestante foi realizado na UBS Maria Anideje (24 horas) do município de Cambé-PR. O convite para as gestantes participarem do grupo 
de orientação foi feito por meio das Agentes Comunitárias de Saúde (ACS), as quais disponibilizaram folhetos informativos, para todas as gestantes da área de abrangência da unidade.

\subsection{Escolha dos temas}

Foram realizados dois ciclos do Grupo de Orientação à Gestante, o primeiro com sete e o segundo com seis encontros. Em reunião realizada com o enfermeiro do PSF, foram definidos temas básicos de maior relevância e interesse para as gestantes. Os temas sugeridos já haviam sido utilizados em grupos anteriores, realizados na mesma UBS, apresentando grande impacto. Desta forma, os temas estabelecidos foram: 1. A importância do pré-natal e as fases da gestação;

2. Medicamentos na gravidez: medicamentos que a gestante pode ou não pode usar durante a gravidez e orientações de uso;

3. Orientação sobre o teste do pezinho e as primeiras vacinas;

4. Aleitamento Materno, nutrição e saúde do bebê;

5. Tipos de parto (normal, cesárea, fórceps), Método Shantalla (massagem no recémnascido);

6. Cuidados com o recém-nascido: banho, curativo do coto, alterações fisiológicas próprias do recém-nascido e organização do enxoval.

7. Volta a atividade sexual e utilização de métodos contraceptivos.

9. Cuidados bucais da mãe e do bebê.

Os temas de 1 a 5 foram abordados em ambos os ciclos. Já os temas 6 e 7 foram abordados somente no primeiro, enquanto que o tema 8 foi abordado somente no segundo.

\subsection{Encontros}

Com o propósito de despertar a atenção e abranger um maior número de gestantes, os encontros foram realizados, semanalmente, antes e durante o horário das consultas de pré-natal, por meio de apresentações orais com duração aproximada de 15 minutos. Após a triagem da enfermagem as gestantes eram direcionadas para uma sala de espera específica, onde foram realizadas todas as reuniões.

Durante as apresentações, além dos temas pré-estabelecidos, foram abordadas situações do dia a dia e, após, a gestante tinha um espaço para trocas e interações entre os presentes.

\subsection{Avaliação dos Resultados}

A avaliação da efetividade do método foi feita por meio de pesquisa de satisfação do usuário. Após cada encontro, cada gestante recebeu um cartão de satisfação, para fazer sua avaliação. Elas contavam com as opções: ótimo, bom e ruim, e também com um campo para sugestões sobre temas de interesse, que pudessem ser abordados em outro ciclo, ou ainda, sobre a metodologia de abordagem do tema.

\subsection{Avaliação das gestantes em relação à atividade desenvolvida}

Como se pode observar na Tabela 1 , em sua avaliação, 82,35\% (14) das gestantes julgou o conteúdo como "ótimo", 17,65\% (3) como "bom" e nenhuma como ruim. Isso nos mostra a importância dos grupos de orientação e da atuação do profissional da saúde nestes, para a troca de informações e preparo da gestante. 
Tabela 1 - Avaliação das gestantes quanto ao conteúdo e método de abordagem.

\begin{tabular}{l|ll}
\hline Opções & Número de gestantes & $\%$ \\
\hline Ótimo & 14 & 82,35 \\
Bom & 3 & 17,65 \\
Ruim & 0 & 0 \\
Total & 17 & 100 \\
\hline
\end{tabular}

Além disso, a atividade foi avaliada de forma positiva pelas participantes, pois, a partir das informações compartilhadas e das metodologias aplicadas, sentiam-se esclarecidas, mais seguras e confiantes para desempenhar seu papel de mãe.

As gestantes não sugeriram mudanças nos temas dos encontros. Com isso, acreditamos que as maiores dúvidas e curiosidades das gestantes se enquadram nos temas abordados.

Segundo Santos \& Penna (2009), a educação em saúde representa um dos principais elementos para a promoção da saúde e, também, uma forma de cuidar, levando ao desenvolvimento de uma consciência crítica e reflexiva. Além disso, contribui para que as pessoas possam cuidar melhor de si e de seus familiares.

Isso nos mostra que a educação em saúde está intimamente relacionada com o cuidado e nos remete ao duplo papel exercido pelos profissionais de saúde que são também educadores por excelência.

Durante o desenvolvimento de ambos os ciclos, pudemos notar um maior interesse e melhor avaliação das participantes nas apresentações onde se abria um espaço para duvidas, fazendo com que as participantes tivessem participação ativa no processo, tornando o ambiente um local de diálogo e trocas de experiências.

Para que as atividades em grupo tenham êxito, é preciso conhecer e ouvir cada participante. A partir de suas necessidades e vivências, é possível avaliar as dificuldades e encontrar a potencialidade do grupo. ${ }^{10}$

Foi relatado pelas gestantes que, além de informações a respeito de fisiologia e diversos cuidados, houve um aprendizado de aspectos simples do cotidiano, considerados importantes para que pudessem cuidar melhor de si e dos filhos.

\subsection{Devolutiva à Unidade de Saúde}

Foi realizado treinamento para os ACS da UBS sobre a importância do grupo de orientação às gestantes, sobre a metodologia utilizada na abordagem do tema e temas de interesse e relevância, com o propósito fim que o grupo de gestante possa continuar existindo sempre na UBS, com o sem o grupo PET-Saúde.

\section{CONSIDERAÇÕES FINAIS}

A estratégia de intervenção realizada pelo grupo PET possibilitou a compreensão que o trabalho educativo não é uma tarefa simples, sobretudo na área da saúde, porque não se limita à transmissão de informações aos usuários em relação ao cuidado de si e de sua família. Ao contrário, é uma prática compartilhada, de troca de saberes, a ser desenvolvida no cotidiano do trabalho em saúde. Para isso, torna-se necessário promover uma prática educativa que visa à participação ativa dos usuários dos serviços de saúde, direcionando esse Revista da ABENO • 13(2):76-81, 2013 
trabalho de acordo com suas necessidades, crenças, representações e histórias de vida, tornando-os, assim, co-responsáveis desse processo educativo, juntamente com os profissionais de saúde, o que torna o grupo uma prática mais atraente.

Tratou-se de uma experiência muito rica para o nosso aprendizado, porque possibilitou uma participação efetiva na UBS, o fortalecimento do vínculo com os profissionais da UBS e também uma aproximação com gestantes, principalmente em relação às suas demandas, expectativas, mitos e medos presentes no período gestacional e também em relação ao cuidado do futuro bebê. Sem dúvidas, o aprendizado no trabalho possibilita uma aproximação maior com a realidade da população.

\section{REFERÊNCIAS}

1. Alves, V. S. Um modelo de educação em saúde para o Programa Saúde da Família: pela integralidade da atenção e reorientação do modelo assistencial. Interface - Comunic, Saúde e Educ., v. 9 n. 16, p. 39-52, 2005.

2. Cremonese, L.; Ressel, L. B.; Wilhelm, L. A.; Rodrigues, B. O. C.; Scaramussa, S. C.; Barreto, C. N.; Silva, S. C.; Stumm, K. E. Grupo de gestantes como estratégia para educação em saúde. Curso de Enfermagem da Universidade Federal de Santa Maria (UFSM), Santa Maria, RS, p. 1-7, 2012.

3. Debald, F. R.; Machado, D. R.; Almeida, G. C. Prática educativa e o Enfermeiro no PSF. Rev. Pleiade, Foz do Iguaçu, v. 2, n. 2, p. 75-96, jul./dez. 2008.

4. Figuerêdo, R. B.; Lima, K. P. S.; Lyra, M. A. V. Trabalhando com grupos: uma experiência de promoção da saúde mental com mulheres grávidas. Facul- dade Integrada do Recife - FIR, P. 1-7, 2008

5. Moreira, C. T. Educação em saúde a gestantes utilizando a estratégia grupo. Rev. RENE, Fortaleza, v. 8, n. 3, p. 107-116, 2007.

6. Neme, B. Obstetrícia básica. $3^{\mathrm{a}}$ ed. Ed. Sarvier, São Paulo; 2005.

7. Reberte, L. M.; Hoga, L. A. K. O desenvolvimento de um grupo de gestantes com a utilização da abordagem corporal. Texto contexto Enferm. AbriJun; 14(2): 186-92, 2005.

8. Santos, M. R. C.; Zellerkraut, H.; Oliveira, L. R. Curso de orientação à gestação: repercussões nos pais que vivenciam o primeiro ciclo gravídico. Rev. O mundo da Saúde, São Paulo, v. 32, n. 4, p. 420-429, 2008.

9. Santos, R. V. \& Penna, C. M. M. A educação em saúde como estratégia para o cuidado à gestante, puérpera e ao recém-nascido. Rev. Texto Contexto Enferm., Florianópolis, v. 18 n. 4, p. 652-660, 2009.

10. Teixeira, E. Práticas educativas em grupo com uma tecnologia sócioeducativa: vivências na Ilha de Caratateua. Esc. Anna Nery Rev. Enferm., v. 11, n. 1, p. 155-159, 2007.

11. Vieira, M. S. Grupo de Gestantes na Equipe Saúde da Família: Proposta de Implantação no Centro de Saúde Confisco, Belo Horizonte, Minas Gerais. Curso de especialização em atenção básica em saúde da família, Belo Horizonte-MG, P. 1-31, 2011.

\section{ABSTRACT \\ Group of expectant mothers/pregnant women: the family PET- Health inter- vention strategy}

In 2013, the Londrina State University Family PET-Health group worked in 
partnership with the Mãe Paranaense (Mothers of Paraná) Program in order to identify the fragilities of the UBSs (Basic Health Units) involved in the Project through interactions with multi-professional teams from each location. From this diagnosis, the Pet group, with the participation of Dentistry and Nursing students, together with the health team, established an intervention strategy to provide positive answers to the UBS demands. Thus, the group worked with the reimplementation of the Expecting Mothers group to contribute to a better welcoming service, the integrality of the attention and the interaction with mothers-to-be, believing that this action could also contribute to the reduction of the curative demands in this part of the population and their babies.

Descriptors: Health Education;Human Resources Formation; Family Health Program. 